\title{
ЭНЕРГОСБЕРЕГАЮЩЕЕ ТЕПЛООБМЕННОЕ ОБОРУДОВАНИЕ ДЛЯ РАЗЛИЧНЫХ СФЕР ПРОМЫШЛЕННОСТИ И ТЕПЛОЭНЕРГЕТИКИ
}

Саввин Н. Ю., Кущев Л. А. БГТУ им. В.Г. Шухова, г. Белгород

Для системь теплоснабжения Российской Федерации характерен значительный износ оборудования: тепловых сетей и котельных. Главным элементом систем теплоснабжения выступают теплообменные аппараты различного конструктивного исполнения. Все рассмотренное оборудование используется в современной теплоэнергетике, на ТЭС и АЭС, котельных и др. Проанализировано устройство и принщип работы теплообменных аппаратов. Установлено, что применение пластинчатых теплообменников является более целесообразным инженерным решением, чем кожухотрубных, ввиду экономических факторов и эксплуатационных преимуществ. Сделаны выводы о необходимости внедрения способов интенсификации теплообмена.

Ключевые слова: теплообмен, пластинчатые теплообменники, кожухотрубные теплообменники, интенсификация, коэффициент теплопередачи.

Структура теплоэнергетического комплекса Российской Федерации насчитывает около 485 ТЭЦ, 6,5 тыс. крупных котельных, более 100 тыс. мелких котельных, мощностью менее 20 Гкал/час, и около 650 тысяч индивидуальных тепловых пунктов (ИТП). Расходы на теплоснабжение страны варьируются в пределах 400 млн. т.У.т./год. Количество работников данной сферы превышает 2,5 млн. человек $[1,2]$.

Ключевое место в промышленной теплоэнергетике и в жилищнокоммунальном хозяйстве страны занимает теплообменное оборудование. Выбор этого оборудования определяется конкретными требованиями и условиями эксплуатации. Наибольшее распространение получили кожухотрубные и пластинчатые теплообменники. В зависимости от условий, рода теплоносителя и назначения аппарата, современное теплообменное оборудование подразделяется на: рекуперативное, регенеративное и смесительное. В статье рассмотрены теплообменники различного конструктивного исполнения, наиболее часто применяемые в промышленности и теплоэнергетике.

В рекуперативных теплообменниках тепло передается от одного теплоносителя к другому через цилиндрическую и плоскую стенку [3]. В свою очередь, теплообменники такого типа можно разделить, в зависимости от конструкции, на кожухотрубные (рис. 1), змеевиковые, спиральные, пластинчатые и др. [4]. 


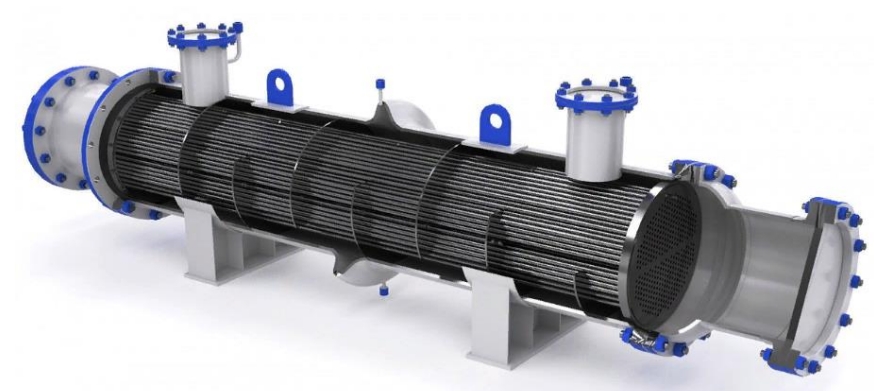

Рис.1 Кожухотрубный теплообменник

Конструкция кожухотрубного теплообменника включает в себя корпус цилиндрический формы с патрубками, предназначенными для ввода и вывода теплоносителей (греющий контур). Корпус содержит секции греющих трубок, изготавливающиеся из нержавеющей стали, меди, латуни и других металлов, с приваренными перегородками в шахматном порядке (нагреваемый контур). Такое деление выполняют с целью интенсификации теплообмена. Чем больше теплопроводность металла, тем выше эффективность.

Главные достоинства кожухотрубных теплообменников - это простота конструкции и обслуживания.

Среди недостатков хотелось бы выделить большие габариты и, как следствие, высокая металлоемкость. Так же при увеличении перегородок наблюдается значительное снижение скорости теплоносителя. Для обеспечения ремонта или отчистки необходима многочисленная бригада и специализированное оборудование, что ведет к большим затратам на обслуживание.

Сравнительно широко в промышленности для охлаждения и конденсации паров применяются змеевиковые теплообменники (рис.2). К их достоинствам можно отнести простоту изготовления и долгий срок службы. Отрицательными качествами являются сравнительно малый температурный диапазон и узкая специализация [5].

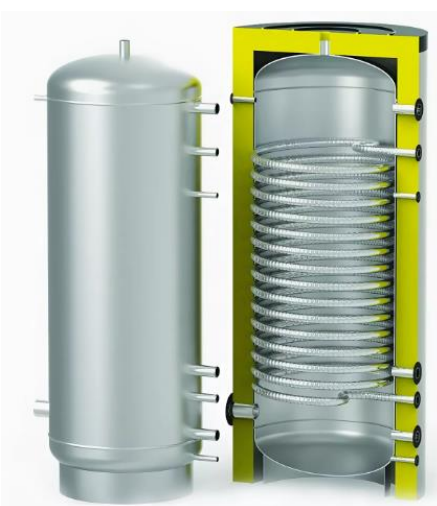

Рис. 2 Змеевиковый теплообменник

Другим техническим решением выступают спиральные теплообменники (рис. 3). Благодаря двум спиральным каналам они и получили свое название. Перегородка соединяет внутренние концы спиралей [6]. 


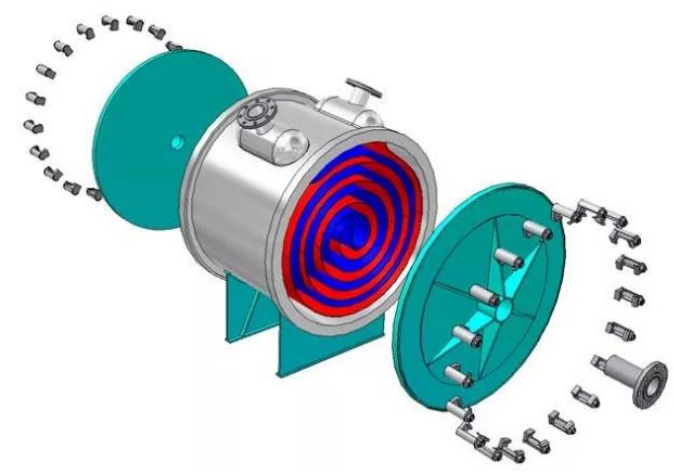

Рис. 3 Спиральные теплообменники

Данный вид теплообменного оборудования нашел свое применение во многих отраслях промышленности. Это обусловлено большой площадью теплопередающей поверхности и высокими скоростями теплоносителя при низких габаритных показателях. В качестве теплоносителя выступают различные жидкости и газы. Кроме того, у спиральных теплообменников низкое значение гидравлического сопротивления.

Среди недостатков можно выделить трудоемкость изготовления, планового ремонта и отчистки.

Использование пластинчатых теплообменников (рис. 4) является инновационным подходом. Для них характерен высокий коэффициент теплопередачи $\boldsymbol{K}, B m /\left(M^{2} K\right)$. Величина коэффициента теплопередачи может достигать 7000 при сравнительно малых габаритных размерах. К достоинствам таких теплообменников можно отнести большую поверхность теплопередачи, которая достигается гофрированием пластин, что дополнительно турбулизирует поток жидкости или газа. Конструкция пластинчатых теплообменников подробно освещена в работе [7].

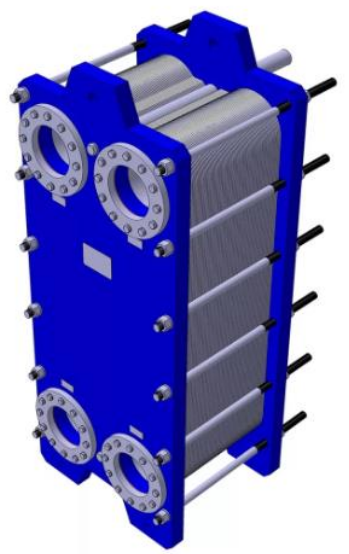

Рис. 4 Пластинчатый теплообменник

Пластинчатые теплообменники применяются в различных сферах промышленности не только в России, но и за рубежом. К недостаткам пластинчатых теплообменников можно отнести:

- сложность изготовления пластин;

- быстрое зарастание поверхностей пластин;

- большая трудоемкость ремонта и эксплуатации. 
Для увеличения поверхности теплообмена и дополнительной турбулизации потока используют теплообменники с гофрированными поверхностями, которые позволяют увеличить площадь поверхности и, соответственно, увеличить коэффициент теплоотдачи $\boldsymbol{\alpha}, \mathrm{Bm} /($ м K).

В технологии гофрирования используются стальные шайбы различных геометрических поверхностей.

Внедрение эффективных способов интенсификации теплообмена направлено на совершенствование теплообменного оборудования и повышение экономичности. Посредством интенсификации теплообмена увеличивается количеством тепла, передаваемого через единицу поверхности теплообмена, и, соответственно, уменьшаются массогабаритные показатели теплообменника.

В итоге, можно сделать вывод, что применение простых в эксплуатации кожухотрубных теплообменников более удобно и выгодно. Главным их недостатком выступает сравнительно низкий коэффициент теплопередачи.

Пластинчатые теплообменники обладают более высоким коэффициентом теплопередачи. Необходимо выделить и другие преимущества: низкая металлоёмкость, оптимальные трудозатраты при ремонте оборудования, высокий КПД. Дальнейшие исследования в области интенсификации процессов теплообмена в пластинчатых теплообменниках позволят увеличить эффективность работы теплоэнергетического комплекса России.

\section{Список литературы}

1. Делягин, Г.Н. Теплогенерирующие установки : учеб. для вузов. Изд. 2-е, перераб. и доп. / Г.Н. Делягин, В.И. Лебедев, Б.А. Пермяков. - М.: БАCTET, 2010. $-623 \mathrm{c}$.

2. Отчет Министерства энергетики РФ «Теплоэнергетика и централизованное теплоснабжение России в 2015 - 2016 годы» Москва: - 2018 - с.138

3. Бухмиров, В.В. Тепловой расчет рекуперативного теплообменного аппарата /В.В. Бухмиров, Д.В. Ракутина, Ю.С. Солнышкова, М.В. Пророкова. - ФГБОУ ВПО «Ивановский государственный энергетический университет имени В.И. Ленина». — Иваново: 2014. — 124с.

4. Никулин, Н.Ю. Современные технологические аспекты развития систем теплоснабжения / Н.Ю. Никулин, Л.А. Кущев, Д.О. Темников // Современное строительство и архитектура. - 2016. - №4. - С. 30-34.

5. Сидельников Л.Н., Юренов В.Н. Котельные установки промышленных предприятий. - М.: Энергоатомиздат, 1988. - 528 с.

6. Павлов К.Ф., Романков П.Г., Носков А.А. Процессы и аппараты химической технологии. - М.: Химия, 1987. - 622 с.

7. Саввин Н.Ю. Высокоэффективный теплообменный аппарат для системы жилищно-коммунального хозяйства /Н.Ю. Саввин, Н.Ю. Никулин; Гадюкина А.В. - Сборник научных трудов в 9 ч. - Новосибирск: НГТУ, 2019. - C. 256-262. 